\title{
Unilateral retinitis pigmentosa occurring in an individual with a mutation in the CLRN1 gene
}

\author{
Peng Yong Sim, ${ }^{1,2}$ V Swetha E Jeganathan, ${ }^{3}$ Alan F. Wright, ${ }^{4}$ Peter Cackett ${ }^{5}$
}

${ }^{1}$ The University of Edinburgh, Edinburgh, UK

${ }^{2}$ Royal Free Hospital, London, UK ${ }^{3}$ The University of Michigan, Ann Arbor, Michigan, USA

${ }^{4} \mathrm{MRC}$ Institute of Genetics and Molecular Medicine,

The University of Edinburgh, Edinburgh, UK

${ }^{5}$ Princess Alexandra Eye Pavilion, Edinburgh, UK

Correspondence to

Dr Peng Yong Sim,

pengyong91@gmail.com

Accepted 28 February 2018

\section{SUMMARY}

This case report depicts the clinical course of a female patient with unilateral retinitis pigmentosa, who first presented at the age of 12 years. Fundus photography at the time revealed unilateral pigmentary retinopathy, which was associated with extinguished electroretinogram (ERG) signal. At 35 years of age, fundus examination revealed deterioration of pre-existing unilateral pigmentary retinopathy with progressive visual field defect detected on Goldmann visual field testing. ERG findings remained unchanged and multifocal ERG showed unilateral decrease in amplitude in the affected eye. The patient was referred for genetic counselling. Next-generation sequencing identified a deleterious heterozygous c. 118T>G (p.Cys40Gly) mutation in the CLRN1 gene.

\section{BACKGROUND}

Retinitis pigmentosa (RP) represents a heterogeneous group of hereditary retinal dystrophies with common clinical and pathological characteristics that include night blindness, contraction of the peripheral visual field and photoreceptor abnormalities which invariably affect both eyes. Unilateral manifestation of this disease, or 'unilateral RP', is reported to be very rare. Since its first description in 1948 by Dreisler, ${ }^{1}<100$ cases of unilateral RP have been reported in the literature. ${ }^{2}$ Furthermore, despite clear clinical and more recently, genetic, evidence supporting existence of true unilateral $\mathrm{RP}^{3-6}$ there remains controversy surrounding the mechanism and existence of this clinical entity.

The purpose of this case report is to report the anatomical and physiological findings from a patient with unilateral RP. From the patient's perspective, it is important to dissect out these details, especially in relation to genetic counselling, considering treatment strategies are limited at present.

\section{CASE PRESENTATION}

Our patient first presented to the ophthalmology department at age 12, with a pale optic disc, arteriolar attenuation and pigment clumping in her peripheral fundus in the right eye. Her left eye was normal. Visual acuities were $6 / 5$ bilaterally. Her birth and medical history were unremarkable, and
Check for updates

To cite: $\operatorname{Sim}$ PY, Jeganathan VSE, Wright AF. et al. BMJ Case Rep Published Online First: [please include Day Month Year]. doi:10.1136/bcr-2017 222045

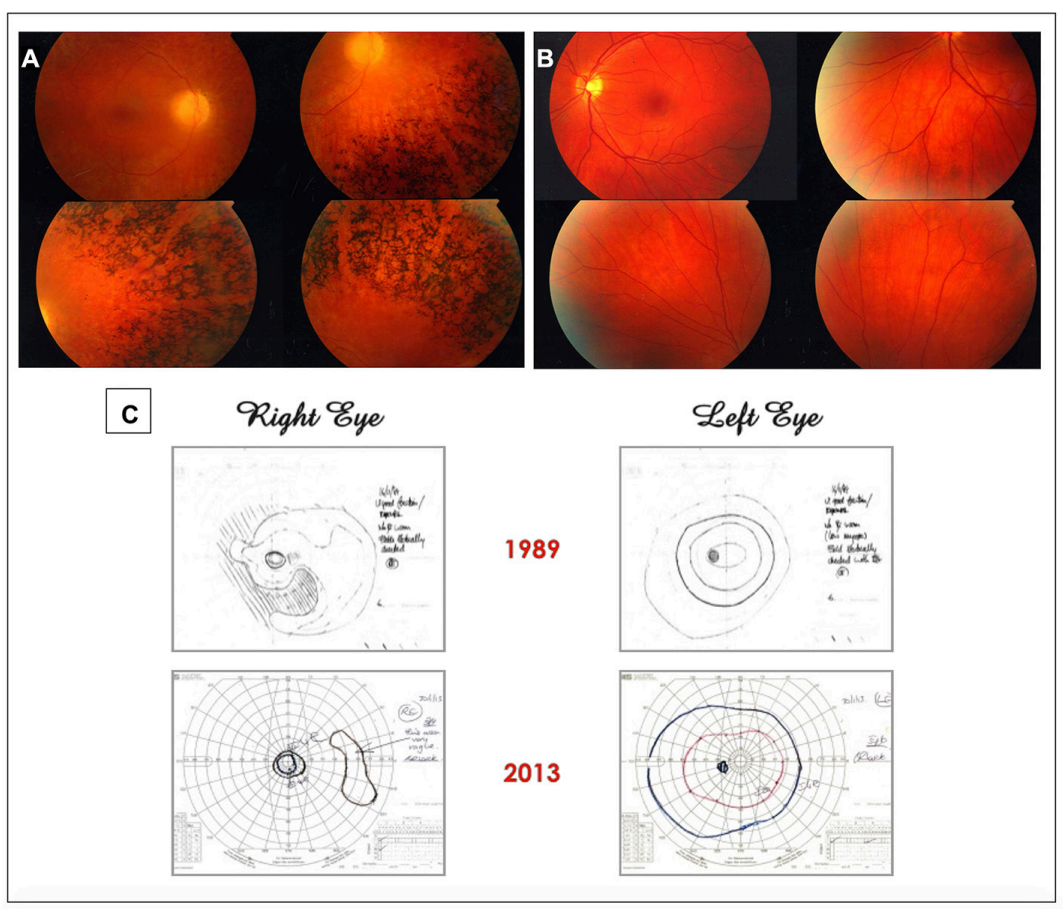

Figure 1 (A) Right fundus photography showing optic disc pallor, arteriolar attenuation and peripheral bone spicule pigmentation. (B) A normal photography of the left eye. (C) Goldmann visual field testing showing a markedly constricted field in the right eye. 


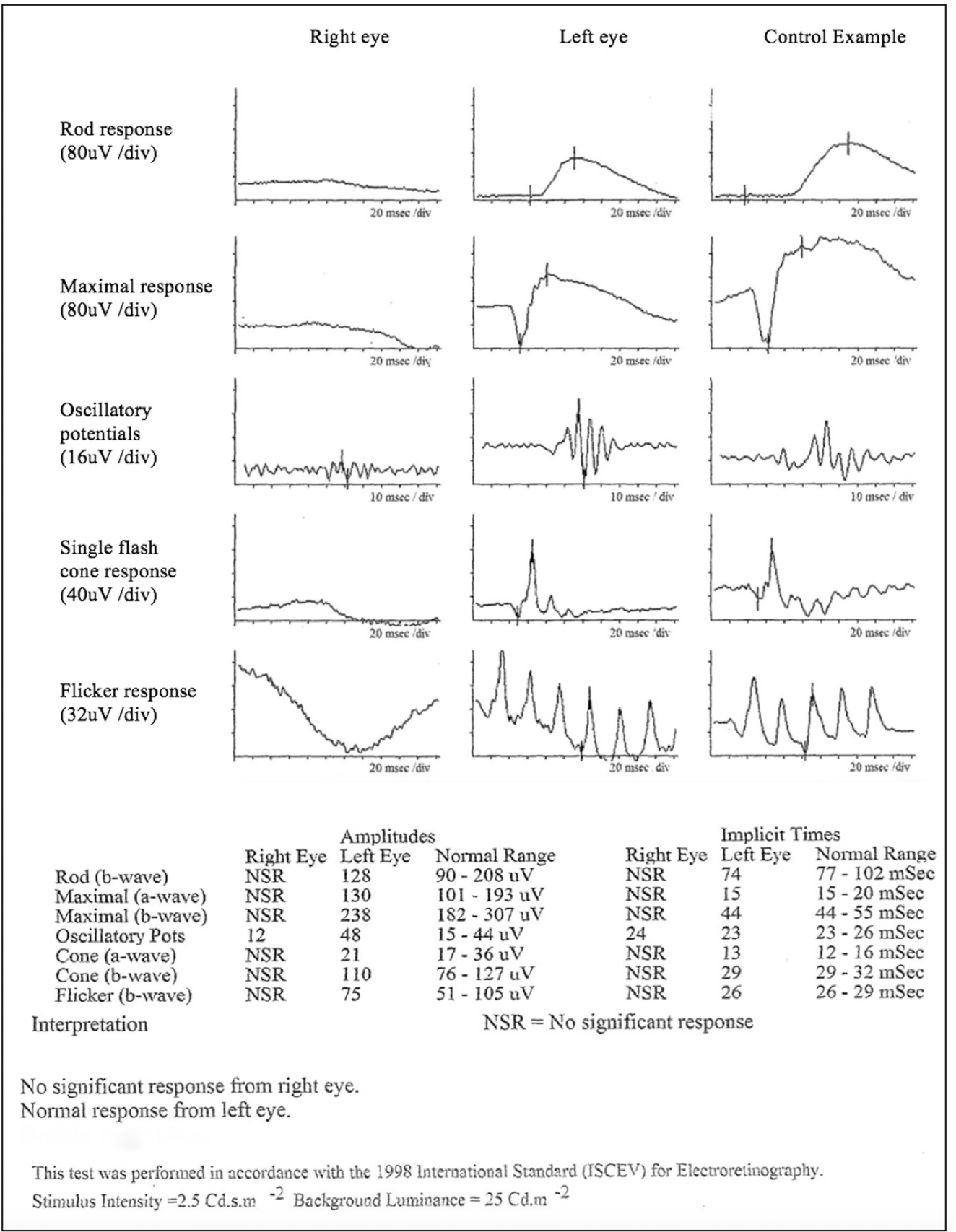

Figure 2 Electroretinogram recordings showing a nearly extinguished signal in the right eye.

all immunisations were up to date. Her hearing and neurological examination were normal. The electroretinogram (ERG) was extinguished in the right eye, and showed normal latencies and amplitude in the left eye. An infection screen at the time was normal.

The patient presented again at age 35 to our ophthalmology department with a gradual decrease in the peripheral vision of her right eye. She denied any previous ocular trauma, surgery or inflammation. Her medical and drug history were unremarkable, with absence of inflammatory disease, prior infections or sexually transmitted diseases. Her hearing and neurological examination remained normal. There was no family history of acquired or inherited eye disease. Visual acuities were 6/9 OD and 6/12 OS. Intraocular pressures were normal. There was a relative afferent pupillary defect and an early posterior subcapsular cataract in her right eye. Dilated fundus examination of the right eye revealed a progression of the lesions found when she presented as a child (figure 1). Her left eye remained completely normal.

\section{INVESTIGATIONS}

\section{Right eye}

Goldmann visual field testing had progressively deteriorated compared with previous visual fields, showing a markedly constricted visual field (figure 1). ERG testing revealed a nearly extinguished signal (figure 2). Multifocal ERG was normal for the central 6 degrees; and severely decreased between 6 and 22 degrees eccentricity and undetectable outside 22 degrees. Dark adaptometry showed marked threshold elevation. Optical coherence tomography confirmed absence of the photoreceptor inner-outer segment junction layer outside the central macula. 


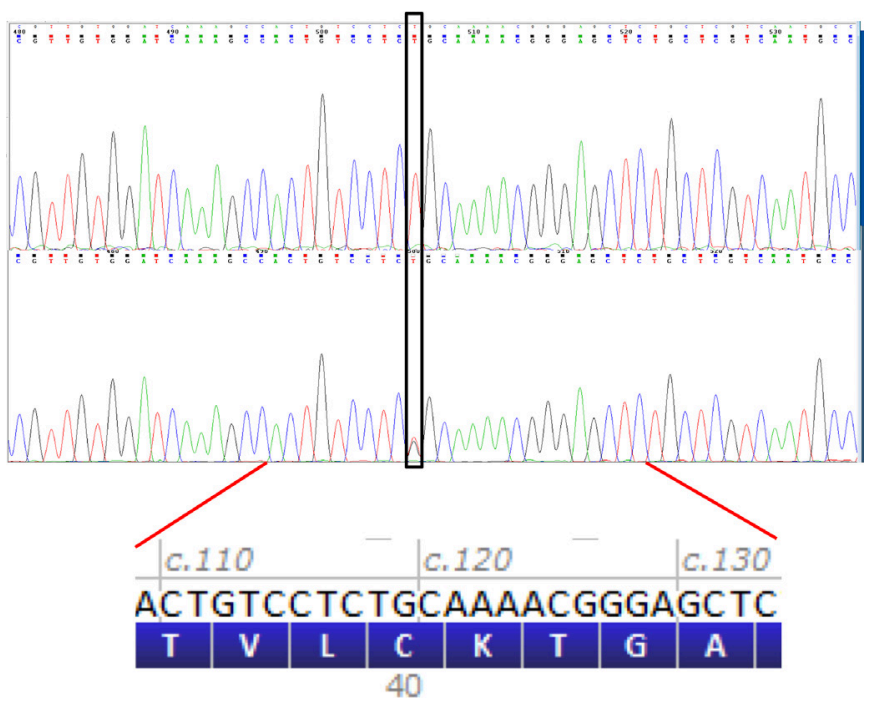

Figure 3 Sanger sequencing results displaying the heterozygous pathogenic CLRN1 mutation c.118T>G (p.Cys40Gly) in our patient (bottom line) compared with the reference sequence (top line).

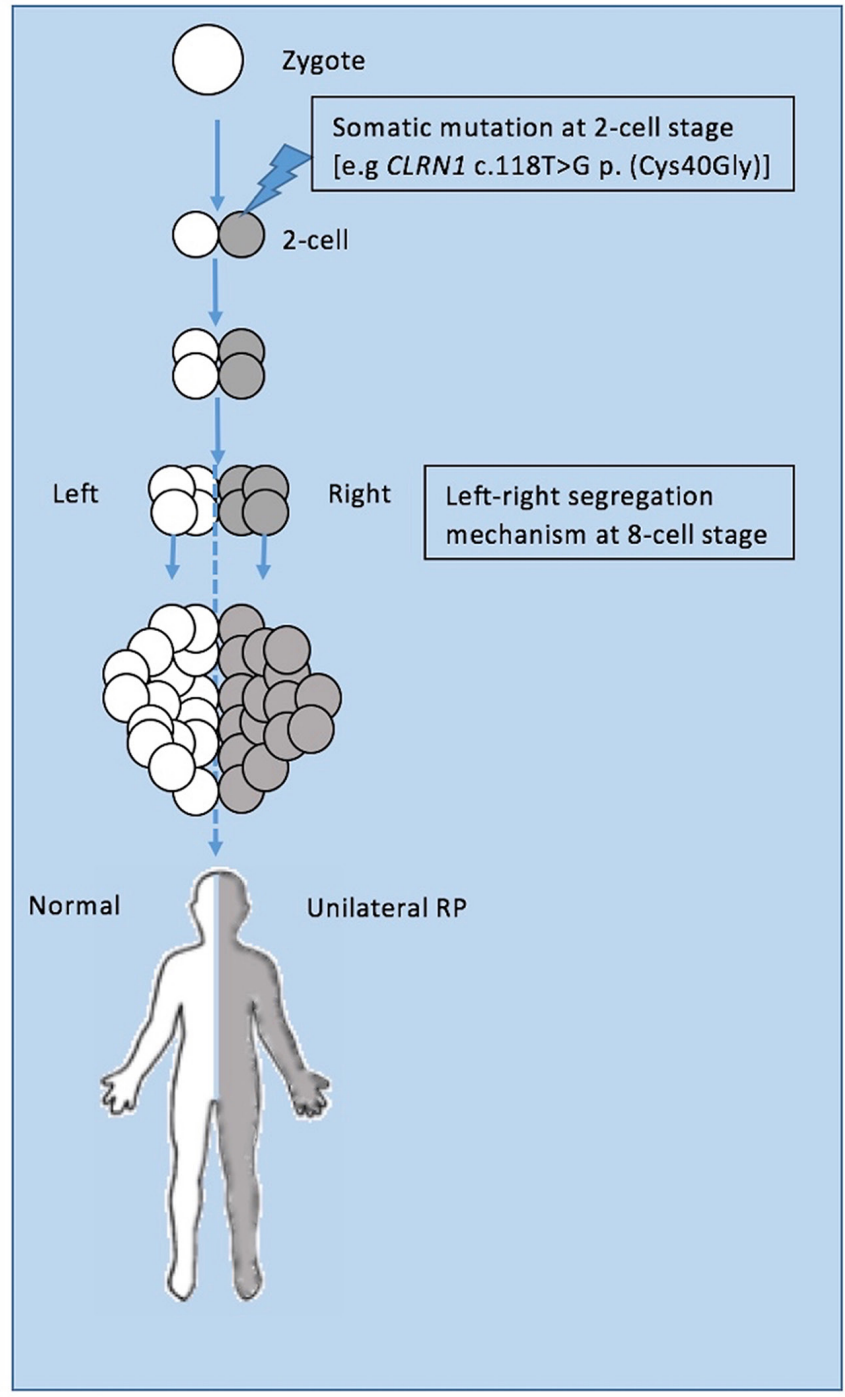

Figure 4 De novo somatic CLRN1 mutation occurring very early in embryogenesis followed by the left-right separation mechanism resulting in unilateral retinitis pigmentosa (RP).
Left eye

All corresponding tests were normal.

\section{DIFFERENTIAL DIAGNOSIS}

Potential causes of unilateral pigmentary retinopathy including tuberculosis, sarcoidosis, Behcet's disease, toxoplasmosis, toxocariasis, rubella, ophthalmomyiasis, syphilis, cytomegalovirus, herpes simplex, diffuse unilateral subacute neuroretinitis (unilateral wipeout syndrome) and occult intraocular foreign body were excluded with detailed clinical and serological examination.

\section{TREATMENT}

None in this case.

\section{OUTCOME AND FOLLOW-UP}

The patient was referred for genetic counselling. Conventional Sanger sequencing revealed no mutation of exon ORF15 of the RPGR gene, or the RP2 gene. However, a 105-gene diagnostic next-generation sequencing (NGS) for inherited retinal diseases ${ }^{7}$ identified a heterozygous pathogenic CLRN1 mutation c. $118 \mathrm{~T}>\mathrm{G}$ (p.Cys40Gly), which was confirmed by bidirectional Sanger sequencing (figure 3). Unfortunately, the patient's parents and siblings were unavailable for genetic testing. The patient remains under regular follow-up in the medical retinal clinic.

\section{DISCUSSION}

The differential diagnosis of unilateral RP includes disorders that closely mimic RP-so-called phenocopies. ${ }^{8}$ Most suspected cases are ultimately explained by phenocopies resulting from inflammation, infection, trauma, autoimmune disease or drug toxicity. In addition, unilateral RP may be the only manifestation of an inherited (germline) but asymmetric RP with a delayed onset in the unaffected eye. Therefore, a valid diagnosis of unilateral RP requires the exclusion of all other explanations for pseudo-RP and confirmation that the clinical signs of RP are truly unilateral by an extended follow-up period of $>5$ years to rule out the possibility of asymmetric inherited RP. ${ }^{9}$ The prolonged follow-up and exclusion of phenocopies have all been fulfilled in this case.

The exact genetic mechanisms underlying unilateral RP remain unclear. Although there have been many documented cases of unilateral RP, mutation confirmation has only been reported in two recent studies. ${ }^{56}$ Even then, the pathogenicity of these mutations has not been functionally proven, leading to speculation as to whether these mutations are responsible for the observed phenotype. There have also been reports of fundus pigmentary changes secondary to the phenomenon of X-inactivation in X-linked RP carrier females. ${ }^{10}{ }^{11}$ However, one would expect segmental changes in both eyes with $\mathrm{X}$-inactivation as opposed to the unilateral manifestation in our patient.

Mutations in the CLRN1 gene have previously been reported in patients with Usher syndrome type 3 and isolated RP. ${ }^{12-14}$ The heterozygous c.118T > G (p.Cys40Gly) mutation detected in our patient has been reported once in the homozygous state in a patient with Usher syndrome type $3,{ }^{15}$ strongly suggesting that it is functionally deleterious. Therefore, it is possible that this heterozygous CLRN1 mutation has manifested as isolated $\mathrm{RP}$ in our patient. However, this does not explain the anatomical asymmetry seen.

Marsiglia et al proposed somatic mutation and mosaicism as possible genetic mechanisms causing unilateral RP. ${ }^{6}$ Although this is an appealing explanation for unilaterality, it does not adequately address the strict confinement of the phenotype to only one of the two eyes. One might expect a degree of 
asymmetry with somatic mosaicism but not the strict demarcation of RP-affected retina as seen in our case.

A plausible explanation for disease unilaterality is the developmental mechanism posited by $\mathrm{Ma},{ }^{16}$ which suggests that embryos of bilaterian animals including humans, are divided into left and right halves at an early embryonic cleavage stage. A somatic mutation before the 8-cell stage would therefore cause somatic mosaicism and if followed by a left-right segregation mechanism, cause unilateral disease due to mutation-bearing cells being confined to one side of the body (figure 4). This extends the somatic mosaicism explanation put forward by Marsiglia et al. ${ }^{6}$

The exact aetiology of unilateral RP, however, remains uncertain in our patient. It is unclear whether the heterozygous CLRN1 mutation is causative or simply coincidental. Due to the high incidence of heterozygosity for autosomal recessive diseases in the normal population, ${ }^{17}$ it is likely that this heterozygous mutation is incidental. Conversely, there remains a possibility that the c. $118 \mathrm{~T}>\mathrm{G}$ (p.Cys40Gly) mutation is causative. There are several examples of RP genes in which heterozygous gain-offunction mutations cause dominant disease while homozygous loss-of-function mutations cause recessive disease (eg, rhodopsin gene) ${ }^{18}$ Assuming that the c. $118 \mathrm{~T}>\mathrm{G}$ (p.Cys40Gly) mutation is causative, it may therefore be dominant or recessive. In the case of recessivity, exome sequencing may have failed to detect a second pathogenic mutation, for example, an intronic mutation affecting RNA splicing. If only one of these mutations is inherited through the germline, a second somatic mutation could cause recessive or digenic RP. Further targeted deletion/ duplication analysis and whole genome sequencing might either detect an additional CLRN1 mutation or a mutation in another gene capable of causing digenic RP. It is also appreciated that the establishment of genetic causality in our patient is further limited by the unavailability of the patient's parents and siblings for further genetic testing.

In summary, we present to the best of our knowledge, the first case report of unilateral RP in a CLRN1 mutation carrier. Although it is likely that the presence of unilateral RP is independent of the CLRN1 mutation detected, there remains a possibility that our patient's phenotype might be caused by this mutation occurring in early embryogenesis to result in strict leftright segregation. The genetic basis of other cases of unilateral

\section{Learning points}

Unilateral retinitis pigmentosa (RP) is an extremely rare variant of RP.

- Diagnosis of unilateral RP can only be made after an extended follow-up period and the exclusion of phenocopies that can mimic RP.

- Genetic workup is becoming increasingly important in dissecting the molecular pathogenesis of rare diseases such as unilateral RP.
RP may be further dissected by NGS approaches, potentially adding to our understanding of RP as a whole. ${ }^{19}$

Acknowledgements Thank you to Professor Baljean Dhillon for his support and advice with this paper.

Contributors PC treated the patient as a clinician. VSJ and PC were responsible for data acquisition, analysis and interpretation. AFW assisted with genetic testing and analysis. PYS and VSJ wrote the first draft of manuscript. VSJ, AFW and PC were involved in revising and critically appraising manuscript. PYS, VSJ, AFW and PC were involved in final approval for publication.

Funding This research received no specific grant from any funding agency in the public, commercial or not-for-profit sectors.

Competing interests None declared.

Patient consent Obtained.

Provenance and peer review Not commissioned; externally peer reviewed.

(c) BMJ Publishing Group Ltd (unless otherwise stated in the text of the article) 2018. All rights reserved. No commercial use is permitted unless otherwise expressly granted.

\section{REFERENCES}

1 Dreisler KK. Unilateral retinitis pigmentosa; two cases. Acta Ophthalmol 1948:26:385-93

2 Farrell DF. Unilateral retinitis pigmentosa and cone-rod dystrophy. Clin Ophthalmol 2009:3:263-70.

3 Chen $\mathrm{H}$, Wu D, Huang S, et al. Unilateral retinitis pigmentosa with amblyopia in the fellow eye. Graefes Arch Clin Exp Ophthalmol 2006;244:1701-4.

4 Thakur A, Puri L. Unilateral retinitis pigmentosa. Clin Exp Optom 2010;93:102-4.

5 Mukhopadhyay R, Holder GE, Moore AT, et al. Unilateral retinitis pigmentosa occurring in an individual with a germline mutation in the RP1 gene. Arch Ophthalmol 2011;129:954-6

6 Marsiglia M, Duncker T, Peiretti E, et al. Unilateral retinitis pigmentosa: a proposal of genetic pathogenic mechanisms. Eur J Ophthalmol 2012;22:654-60.

7 Ellingford JM, Barton S, Bhaskar S, et al. Molecular findings from 537 individuals with inherited retinal disease. J Med Genet 2016:761-7.

8 Sharma YR, Reddy PRR, Singh D V. Retinitis pigmentosa and allied disorders. JK Sci 2004:6:115-20.

9 Francois J, Verriest G. [Retinitis pigmentosa unilateral]. Ophthalmologica 1952;124:65-88.

10 Neidhardt J, Glaus E, Lorenz B, et al. Identification of novel mutations in X-linked retinitis pigmentosa families and implications for diagnostic testing. Mol Vis 2008;14:1081-93.

11 Comander J, Weigel-DiFranco C, Sandberg MA, et al. Visual function in carriers of x-linked retinitis pigmentosa. Ophthalmology 2015;122:1899-906.

12 Khan Ml, Kersten FF, Azam M, et al. CLRN1 mutations cause nonsyndromic retinitis pigmentosa. Ophthalmology 2011;118:1444-8.

13 Västinsalo $H$, Jalkanen $R$, Dinculescu A, et al. Alternative splice variants of the USH3A gene Clarin 1 (CLRN1). Eur J Hum Genet 2011;19:30-5.

14. García-García G, Aparisi MJ, Rodrigo R, et al. Two novel disease-causing mutations in the CLRN1 gene in patients with Usher syndrome type 3. Mol Vis 2012;18:3070-8.

15 Aller E, Jaijo T, Oltra S, et al. Mutation screening of USH3 gene (clarin-1) in Spanish patients with Usher syndrome: low prevalence and phenotypic variability. Clin Genet 2004;66:525-9.

16 Ma K. Embryonic left-right separation mechanism allows confinement of mutationinduced phenotypes to one lateral body half of bilaterians. Am J Med Genet $A$ 2013;161A:3095-114.

17 Cooper DN, Krawczak M, Polychronakos C, et al. Where genotype is not predictive of phenotype: towards an understanding of the molecular basis of reduced penetrance in human inherited disease. Hum Genet 2013;132:1077-130.

18 Ferrari S, Di lorio E, Barbaro V, et al. Retinitis pigmentosa: genes and disease mechanisms. Curr Genomics 2011:12:238-49.

19 Neveling K, Collin RW, Gilissen C, et al. Next-generation genetic testing for retinitis pigmentosa. Hum Mutat 2012;33:963-72. 
Copyright 2018 BMJ Publishing Group. All rights reserved. For permission to reuse any of this content visit http://group.bmj.com/group/rights-licensing/permissions.

BMJ Case Report Fellows may re-use this article for personal use and teaching without any further permission.

Become a Fellow of BMJ Case Reports today and you can:

- Submit as many cases as you like

- Enjoy fast sympathetic peer review and rapid publication of accepted articles

Access all the published articles

- Re-use any of the published material for personal use and teaching without further permission

For information on Institutional Fellowships contact consortiasales@bmjgroup.com

Visit casereports.bmj.com for more articles like this and to become a Fellow 